\section{Evolutionary ecology}

\section{Toxins and grazing resistance}

\section{Peter D. Moore}

ONE: of the most useful things about plants, where human beings are concerned, is their capacity to resist the attentions of grazing organisms by the production of deterrent chemicals. These secondary compounds are among the most important controls on grazing insects' and by happy chance provide a rich source of drugs, for example, caffeine: Considerable effort is now being directed towards the study of plant/grazer interactions as a potential source of pesticides and drugs, and simply as an area in which co-evolution is most graphically illustrated. Some recent investigations seek to demonstrate the importance of secondary compounds in a range of lower plants, including cycads", lichens ${ }^{+}$and algaé, as well as in higher aquatic plants".

Cycads are well known as plants toxic to vertebrates', but the North American cycad Zamia floridana is fed upon by the brightly coloured caterpillar of a Lycaenid butterfly, Eumaeus atala. It has been supposed that the red and yellow

Unpalatable meals? Larvae of Eumaeus atala florida (photocoloration of the larva indicates that it sequesters glycosides for its own defence, as is the case in the monarch butterfly", but the study of this particular plant/animal inter-relationship has been hampered by the extreme rarity of the insect. A captive hreeding programme has now provided

\section{0 years ago}

I wish to suggest a possibility. which if truc will considerably alter our views of the lates of chemistry. Let us take the electrolysis of hydrochloric acid

At present we state the facts thus: Every molecule of hydrochloric acid consists of one atom of chlorinc and one atom of hydrogen, the chlorine atom weighing 35.5 , the hydrogen atom weighing 1 . ()n passing a current, each molecule is split into these two atoms. each atom carrying a unit charge of electricity.

It is met just possible that we may some day state: A molecule of hydrochloric acid comsists of onc molecule of hydrogen weighing $1 \mathrm{com}$ bined with 35.5 molecules of chlorine each weighing 1. (On clectrolysis, the chlorine atoms are split from the hydrogen atom, the chlorine atoms each carrying unit charge of electricity. and the hydrogen atom carrying 35.5 charges of electricity. If this is the truth. then all the atoms of the elements are of the same weight, and probably are mate of the same "stuff", and we have only two things which condition the properties of the atom - its electrical charge and its electric polential. and Mendelejeff's table becomes a statemem of the periodic relationship between these.

From Nature 35, 1.32: 9 December 1886. sufficient larvac to permit analysis and Rothschild, Nash and Bell ${ }^{3}$ report that both the caterpillars and the adult insects do indeed contain the glycoside cycasin and are therefore toxic to predators. They also emit a pyrazine-like odour which presumably deters enemies. Their conspicuous coloration, also a deterrent, is unusual almong the Lycaenids, suggesting that the association between cycad and

\section{IMAGE UNAVAILABLE FOR COPYRIGHT REASONS}

for their own protection against predators. The sea hare Aplysia californica, a marine mollusc, is though to do this with the sesquiterpenes of Laurencia pacifica". But it is evident that not all the grazing effects of herbivores on algae are necessarily harmful to the plant. Zooplankton may stimulate phytoplankton growth rates by local enrichment of water with ammonia ${ }^{10}$; Connor and Quinn" propose that growth of some microalgae is stimulated by the mucus of grazing limpets.

But Crews and Selover now suggest that Erythrocystis saccata, a red algae semi-parasitic on $L$. pacifica, may take up sesquiterpenes from its host and retain them in the same concentration in its own thallus. They have not demonstrated actual transport, but any other source of this particular suite of compounds seems unlikely. Perhaps the parasite gains some degree of predator immunity from the sequestered defence materials.

It is not only the algae among aquatic plants that are well equipped to deal with the attentions of grazers. Ostrofsky and Zettler ${ }^{n}$ show that the same is true of many aquatic higher plants, such as some species of the pondweed genus Potamogeton. Possession of deterrent secondary compounds may account for the low level of herbinteresting to know whether the cycad receives any benefit from the relationship, perhaps in the form of pollination.

Down the scale of evolutionary complexity, secondary compounds in the lichens are also implicated in herbivore deterrence. Lawrey examined the behaviour of slugs when presented with a selection of lichens and found that they exhibit a distinct preference for certain species - perhaps it would be more accurate to say that they definitely avoid the unpalatable species. Even acetone extracts of the thalli of avoided species are effective in deterring the predators. The fact that it is avoidance of the distasteful rather than preference for the attractive which operates is shown by the higher levels of nitrogen, phosphorus, potassium and calcium in the avoided species. Those lichen species, which should have been most alluring to the slugs, are in fact the most distasteful because of their heavy load of secondary compounds.

In marine algate, there are secondary compounds which could also be involved in grazing resistance. For example. many species of the red alga genus Laurencia have sesquiterpenes, compounds which are often involved as insect deterrents in higher plants". There are even parallels to the terrestrial grazers which have an immunity to toxins or even store them ivore attack on such species. P. crispus is particularly well supplied with alkaloids and the authors consider that the concentrations present $(0.2-0.5 \mathrm{mg}$ per g dry weight) are adequate to account for the general lack of grazing on such aquatic macrophytes. But some terrestrial mammals are known to graze on aquatic plants, for example the moose, which derives most of its sodium requirement from summer grazing in shallow lakes'2. Perhaps this animal, like the sheep ${ }^{13}$, has some degree of resistance to the alkaloids contained in the aquatic macrophytes and thus takes advantage of a relatively underexploited resource.

Matugh. T.H. Science 216, $722-723$ (1982)

Rohhschitd. M.. Nash. R.J. \& Bell. F A Phrechemistry 25, $185.3-1854(1986)$

4. I.awrey J J) Am. J Bot 70, 1188 1194 (1983)

5. ('rews. P. \& Solover. S.J Phytentemstri 25, 1847 - 1852 (19)86).

6. Ostrofsky, M I \& Zettler. E.R. J R Rol 74, 279-287 (1986)

7. Deluca. P. Mforetti. A. Satbato, S. \& Gigliano G.S Phyochemisers 19, 2230 - 2232(1980)

8. Fink. L.S. \& Brower. L.P. Nature 291, 67 - 70)(1981)

9. Hitrhorne, J.B. Introduction to Ecological Biochemistry (Academic. London. 1982)

II. Sterner. R.W. Science 231, 605-607(1486)

II. Connor. V.M. \& Ouinn. J.F. Science 225, $8+3-844$ (1984).

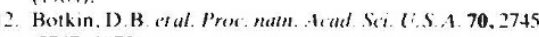
$2747(197.3)$.

13 (irime, J.P. a al. J. ticol. 56. $4(15-.42)(1968)$

Peter D. Moore is in the Biology Department, King's College London $(K Q C)$, Campden Hill Road, London W8 7AH, UK.
Nathanson. J.A Science 226, 184 - 187 (1984) 